\title{
The Effect of Electrolyte Ingredients on Electrolyte-Electrode Interface in Electrocoating: A Comparative Study
}

\author{
Hacer Dolas ${ }^{1}$, Keziban Huner ${ }^{2}$ and A.Sezai Sarac ${ }^{3 *}$ \\ 1. Program of Occupational Health and Safety, Hilvan Vocational School, Harran University, 63900, \\ Sanliurfa, Turkey \\ 2. Department of Chemistry, Yildiz Technical University, 34349, Davutpasa, Istanbul, Turkey \\ 3. Department of Chemistry and Polymer Science \& Technology, Istanbul Technical University, 34467, \\ Maslak, Istanbul, Turkey \\ Corresponding author: sarac@itu.edu.tr
}

\begin{abstract}
In this study, $\mathrm{CFs}$ were coated electrochemically with three different monomers (An, EDOT or Py) in different condition such as electrolyte $\left(B A, \mathrm{H}_{2} \mathrm{SO}_{4}\right.$ or $\left.\mathrm{NaClO}_{4}\right)$, solvent $\left(\mathrm{H}_{2} \mathrm{O}\right.$ as inorganic medium or ACN as organic medium), in presence of foreign material (EBC) and coating method (constant potential and cyclic voltammetry as controlled potential). Obtained $\mathrm{CFs}$ were compared with regard to electrical and capacitive and morphological features.

In CPE the current flown in system was changed in certain values for each monomer in presence of EBC. But this changing was more for Py than that for the other. In CV experiments, the oxidation potential was increased for PAn and PEDOT when it was decreased for Py. Imax values were changed for each polymer and conditions. According to Randles-Sevcik equation, the electrocoating redox processes in $\mathrm{BA}-\mathrm{H}_{2} \mathrm{O}$ were not controlled by diffusion under this conditions. But, all the redox processes carried out in $\mathrm{NaClO}_{4}-\mathrm{ACN}$ electrolyte solution were controlled by diffusion for each polymer coated CFs. In presence of EBC it could be concluded that redox process was controlled by diffusion in $\mathrm{BA}-\mathrm{H}_{2} \mathrm{O}$ for PAn and in $\mathrm{NaClO}_{4}-\mathrm{ACN}$ for PEDOT.

In presence of $1.8 \% \mathrm{EBC}$. The $\mathrm{C}_{\mathrm{DL}}$ value was decreased to $4 \mu \mathrm{F}$ from $6 \mu \mathrm{F}$; to $0.7 \mu \mathrm{F}$ from $1.5 \mu \mathrm{F}$; to $1 \mu \mathrm{F}$ from $3 \mu \mathrm{F}$ in BA- $\mathrm{H}_{2} \mathrm{O}$ for Pan, PEDOT and PPy respectively. But, it was increased to $11.5 \mu \mathrm{F}$ from $10.4 \mu \mathrm{F}$ in $\mathrm{NaClO}_{4}-\mathrm{ACN}$ for PEDOT. Phase angle was in the same trend.

The texture coatings were more compact in the presence of EBC in electrolyte solution than that of the absence of EBC for PPy coated CF. The relationship of between the radius of coating and the $\mathrm{C}_{\mathrm{DL}}$ of the coated $\mathrm{CF}$ was proportional. Thus, it may be concluded that the $\mathrm{C}_{\mathrm{DL}}$ and radius of coating were affected with the presence of different material/compound in electrolyte solution.
\end{abstract}

Keywords: PAn, PEDOT, PPy, presence of EBC, comparison, impedance, texture coating.

DOI: $10.7176 / \mathrm{CMR} / 13-3-05$

Publication date:November $30^{\text {th }} 2021$

\section{Introduction}

Carbon fibers (CFs) have properties such as high strength and modulus, good stiffness, and creep resistance etc. For this reason, they have been used as the reinforcing material in the high performance resin composites which have been extensively used in a variety of areas such as the aerospace industry, automobile applications and sporting goods (Montes-Moran et.al. 2004).

Fibers and a matrix material (polymer resin) make interactively a new combination. One of the major advantages of the fiber/resin combination is its complementary nature. Others are that numerous method such as the electrochemical oxidation (Yue et.al. 1999; Gulyas et. al. 2001 \& Febo et. al. 2002), plasma treatment (MontesMoran et.al. 2001; Dilsiz et.al. 1995 \& Bubert et.al. 2002), radiation treatment (Li et.al. 2005 \& Xu et.al. 2007) methods, etc., have been used to treat the CFs surface in order to improve the interfacial performance between fiber and matrix.

In addition to the different methods, electrocoating with thin conductive polymer film is proposed by our group as feasible approach to add functionality onto the carbon fiber surface covalently (Kumru et.al. 2001). The film thickness, morphology and functionality of the formed coating can be precisely controlled with electrochemical coating method using following parameters i.e., current density, potential, monomer concentration, and scan rate etc. (Sarac et.al. 2008; Dolas \& Sarac 2012).

Some polymers show conductive feature. This information is not known by the time the discovery of a polyacetylene (PA) thanks to that Shirakawa et.al. (1977) reported about conducting concept in the polymer. 
These polymers have conjugation structure along polymer chain. The electron flow in the polymer chain is possible thank for this conjugation structure. They are known as conducting polymers (CPs) due to their conducting features. Polypyrrole (PPy), polyaniline (PANI), Poly(3, 4- ethylenedioxyhiophene) (PEDOT), and Polythiophene (PTh) are CPs studied intensely. Due to having low band gap and low redox potential these polymers show high conductivity (Cysewska et.al. 2015 \& Groenendaal et.al. 2000). While PEDOT has good chemical stability (Kulandaivalu et.al. 2015; Patil et.al. 2016 \& Patil et.al. 2016), PANI has good environmental, and thermal stability $\left(250^{\circ} \mathrm{C}\right)$ (Kawashima \& Goto 2011; Ma et.al. 2016) and PPy shows good redox reversibility (Li et.al. 2007) \& Jeong et.al. 1998).

The polymerization of the thiophene ring simplifies when a ethylenedioxythiophene group substitutes at the 2position of the thiophene ring, due to decreasing electron density in the ring. So, formed the linear chains are more stable than the thiophene analogous. Also, the oxidation potential of EDOT monomer is shifted at lower values because of chain is more stable. This stability is provided via the presence of the substituent containing electron-donating oxygen. the oxidation potential of (Ahmed et.al. 2012 \& Ahonen et.al. 2000).

Emeraldine is the conducting form of PANI. This form composed of benzenoid or quinoid rings is one of the different oxidation form of PANI (Dhawan et.al. 1997; Jaymand 2013 \& Bhadra et. al. 2009).

PPy is made of from repeating unit of pyrrole ring. This formation provides to PPy extended $\pi$-conjugated backbone along chain (Wei et. al. 1991 \& Saville 2005).

Electrochemical Impedance Spectroscopy (EIS) is an experimental method for characterizing electrochemical systems. This method measures the impedance of the electrochemical coated carbon fiber (CF) over a range of frequencies, and the frequency response of the coated $\mathrm{CF}$ is determined, including the energy storage and dissipation properties, capacitive properties.

An electrical double layer forms between electrolyte and coated CF surface. This layer means electrolyte/electrode interface of a coated CF and this interface plays an important role for controlling properties such as double layer capacitance of composite and interactions on the coated surface. The capacitive behavior of coated CF was affected, as electrolyte ingredients changed. Because type and ingredients of electrolyte solution determined dielectric properties of the solution. This effect was seen in our previous studies, but was not investigated in detail.

In the presented study, we were aimed to investigate the electrical, capacitive and morphological features of the CF coated with different conducting polymers (PEDOT, PANI and PPy) and different electrolyte type (boric acid, BA, sulphuric acid, $\mathrm{H}_{2} \mathrm{SO}_{4}$ and sodium per chloride, $\mathrm{NaClO}_{4}$, epoxy) and different solvent type (acetonitrile, $\mathrm{ACN}$ and /or Pure water, $\mathrm{H}_{2} \mathrm{O}$ ), comparatively. As result, we found that these parameters were affected both capacitive and electrochemical properties of coated $\mathrm{CF}$ and that a proportional relationship was between the morphological and the capacitive features.

\section{Experimental:}

Aniline (An), 3,4-Ethylenedioxythiophene (EDOT) and Pyrrole (Py) were selected as monomer. Each monomer was prepared as $0.01 \mathrm{M}$. Boric acid (BA), sulphuric acid $\left(\mathrm{H}_{2} \mathrm{SO}_{4}\right)$ and sodium perchlorate $\left(\mathrm{NaClO}_{4}\right)$ as electrolyte; pure water $\left(\mathrm{H}_{2} \mathrm{O}\right)$ or acetonitrile $(\mathrm{ACN})$ as solvent were used. The electrolyte solution used in experimental tests was prepared and used as $5 \mathrm{ml} 0.1 \mathrm{M}$. Electropolymerization tests were carried out by two different electropolymerization methods, Constant Potential Electropolymerization (CPE) and Cyclic Voltammetry (CV) in three electrode system. In this system Ag wire was used as reference electrode (calibrated with $0,1 \mathrm{M}$ ferrocene), Pt wire as counter electrode and Carbon Fiber (CF) as working electrode. Working electrode was prepared in brush form $(0.003+-0.0005 \mathrm{~g}$ and $6 \mathrm{~cm})$ for CPE tests and in single fiber form for CV tests. Epoxy based compound (EBC, Chemetylen AK-2) was provided from SANYO Chemical Industries, Ltd.

\section{Results and discussion:}

\subsection{The Constant Potential Electropolymerization (CPE):}

To investigate the effect of different polymer on electrical behavior of $\mathrm{CF}$, the CFs in form of brush were electrocoated with different polymers (PAn, PEDOT and PPy) at constant potential (1V) produced by a power supply in the same electrolyte medium. In this part EBC was not added in the electrolyte media. Obtained data were plotted in Figure 1. 

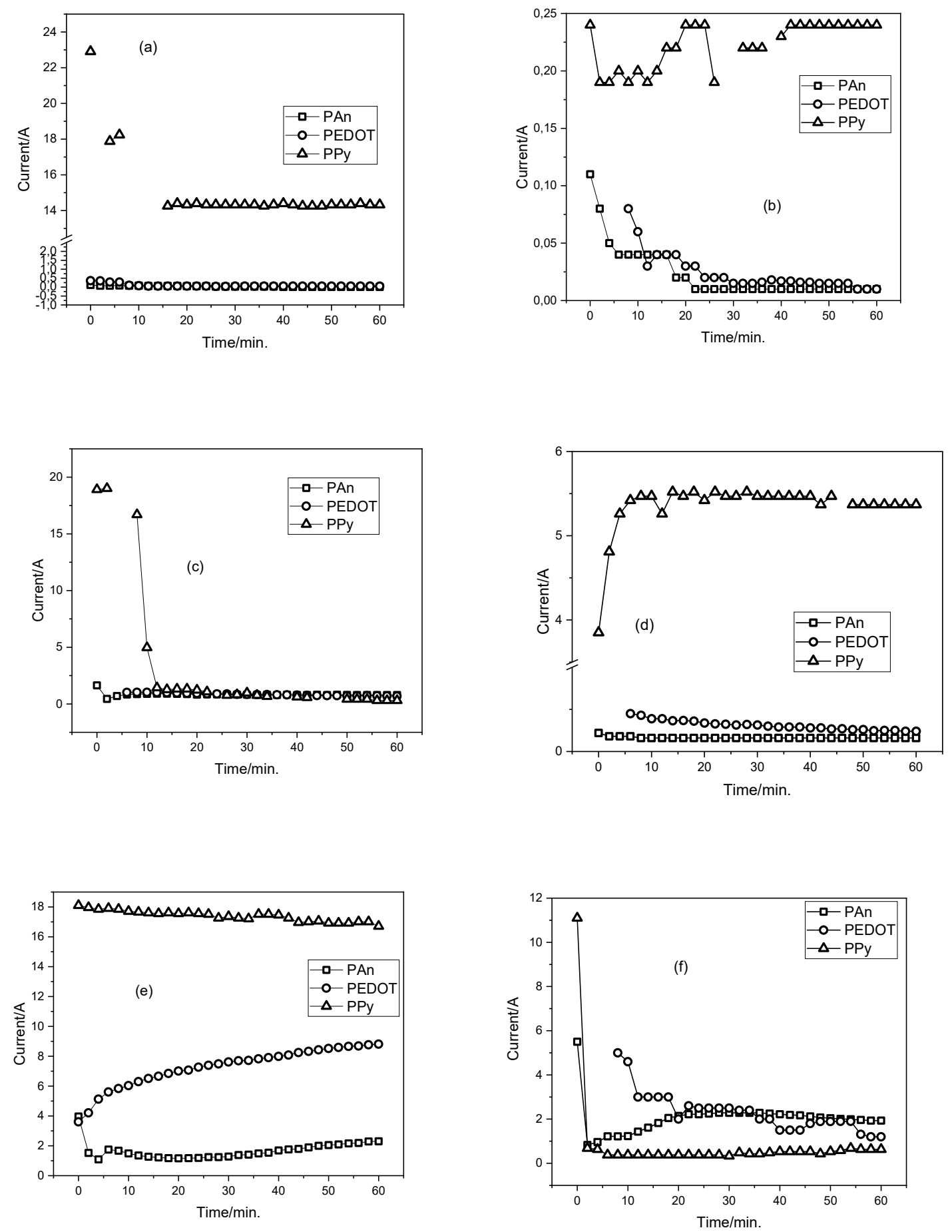

Figure 1. The Current-Time graph. a) BA- $\mathrm{H}_{2} \mathrm{O}-0 \%$ EBC; b) BA- $\mathrm{H}_{2} \mathrm{O}-1.8 \% \mathrm{EBC}$; c) $\mathrm{H}_{2} \mathrm{SO}_{4}-\mathrm{H}_{2} \mathrm{O}-0 \%$ EBC; d) $\mathrm{H}_{2} \mathrm{SO}_{4}-\mathrm{H}_{2} \mathrm{O}-1,8 \%$ EBC; e) $\mathrm{NaClO}_{4}-\mathrm{ACN}-0 \%$ EBC; f) $\mathrm{NaClO}_{4}-\mathrm{ACN}-1.8 \%$ EBC. (monomer concentration: $0.1 \mathrm{M})$

The species in electrolyte solution such as solvent, monomer or other material affected electron movement in 
solution due to ionic strength and/or action with each other. For this reason, formed current in solution was increased or decreased. As seen from figure 1c current data passed system was reached to about range of 6-7 A for PEDOT sample, 1-1.5A for Pan and 17-18 A for PPy in $\mathrm{NaClO}_{4}-\mathrm{ACN}$, compared with the other solution media. Current flown in system was decreased in $\mathrm{BA}-\mathrm{H}_{2} \mathrm{O}$ and $\mathrm{H}_{2} \mathrm{SO}_{4}-\mathrm{H}_{2} \mathrm{O}$ medium due to the interaction of monomer and electrolyte.

To see the effect of different a material in electrolyte solution, given above experimental conditions were repeated by adding the EBC in electrolyte solution as \%1.8 (w/w). Obtained data were plotted in Figure 1b, d, and $\mathrm{f}$, comparatively with $0 \%$ EBC.

It was seen that the current flown in system was decreased/increased in certain values for each monomer. But this changing was more for Py than that for the other. When it was not remarkably for An and EDOT monomers from the Fig, with compared to Py. So, the current value was changed to 0.24 from $14.33 \mathrm{~A}$ in $\mathrm{BA}-\mathrm{H}_{2} \mathrm{O}$, to 5.37 from $0.31 \mathrm{~A}$ in $\mathrm{H}_{2} \mathrm{SO}_{4}-\mathrm{H}_{2} \mathrm{O}$, to 0.63 from $16.71 \mathrm{~A}$ in $\mathrm{NaClO}_{4}-\mathrm{ACN}$ for Py; to 0.01 from $0.05 \mathrm{~A}$ in $\mathrm{BA}-\mathrm{H}_{2} \mathrm{O}$, to 0.24 from $0.69 \mathrm{~A}$ in $\mathrm{H}_{2} \mathrm{SO}_{4}-\mathrm{H}_{2} \mathrm{O}$, to 1.2 from $8.81 \mathrm{~A}$ in $\mathrm{NaClO}_{4}-\mathrm{ACN}$ for EDOT; to 0.01 from 0.01 in BA- $\mathrm{H}_{2} \mathrm{O}$, to 0.16 from $0.79 \mathrm{~A}$ in $\mathrm{H}_{2} \mathrm{SO}_{4}-\mathrm{H}_{2} \mathrm{O}$, to 1.93 from $2.3 \mathrm{~A}$ in $\mathrm{NaClO}_{4}-\mathrm{ACN}$ for An. This case could be attributed the interaction of between monomer or electrolyte and $\mathrm{EBC}$.

Obtained coated CFs with conducting polymer in different experimental conditions were weighed at analytical balance to investigate the relation of condition-coating weight. The coated $\mathrm{CF}$ was dried in air and weighed. The weight of uncoated CF was subtracted from this value. Obtained data were given in Figure 2.

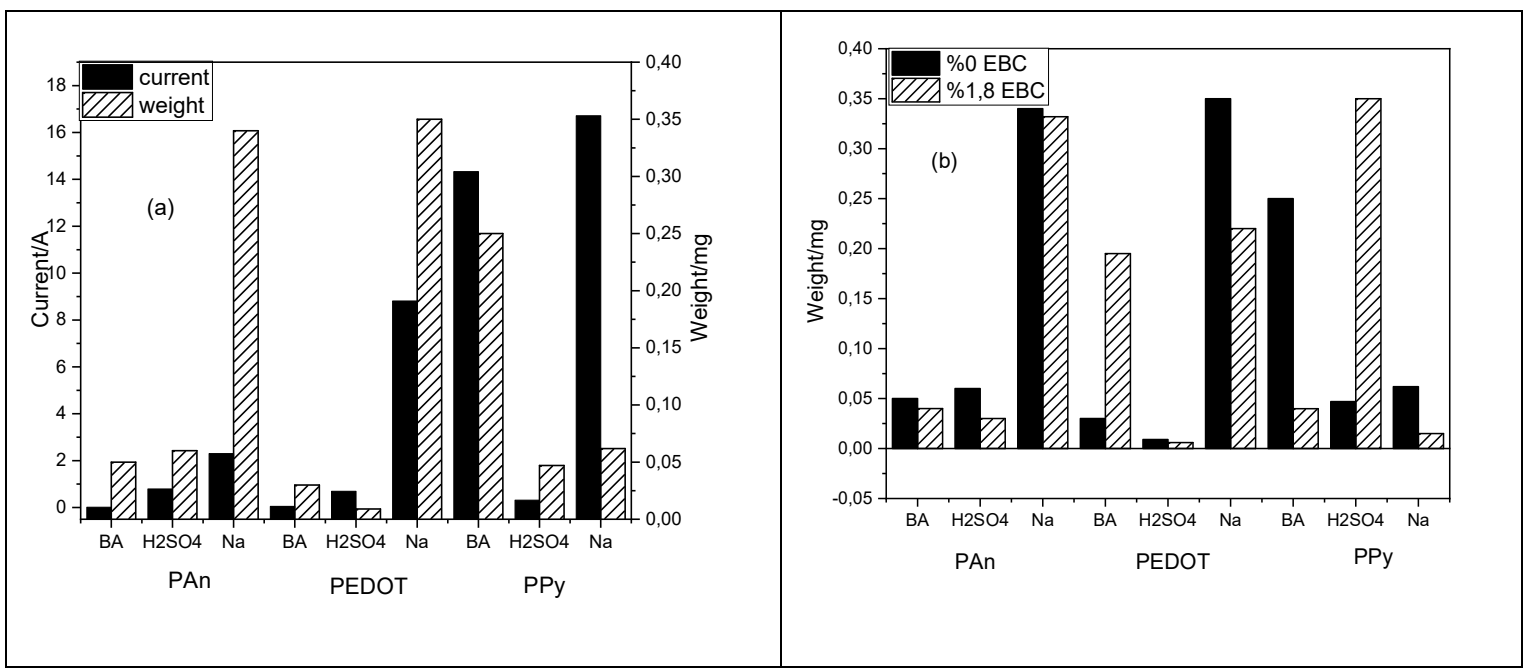

Figure 2. The graph of the Current passed in system -the Weight of coating by CPE method. a) $0 \%$ EBC; b) comparison.

It was seen that the weight of coating was increased for PAn sample in different electrolyte medium as current was increased. This changing was observed as decreasing in presence of $\% 1.8 \mathrm{EBC}$ (Figure $2 \mathrm{~b}$ ). So, the weight of coating was decreased in different electrolyte medium in presence of \%1.8 EBC, in parallel with the current. For PEDOT and PPy this manner was different. The weight was increased in presence of EBC in BA for PEDOT, in $\mathrm{H}_{2} \mathrm{SO}_{4}$ for PPy even though the current was decreased. This case might be excess of $\mathrm{H}^{+}$ions in electrolyte medium.

It was though that the impedance value of the coated CF with conducting polymer was affected by electrocoating conditions. For this reason, the coated CFs obtained in various conditions were electro performed in monomer free electrolyte solution at different scan rates. To evaluate the impedance of the CFs, the double layer capacitance $\left(\mathrm{C}_{\mathrm{DL}}\right)$ and the Phase Angle of coated CF were plotted Figure 3, comparatively. 

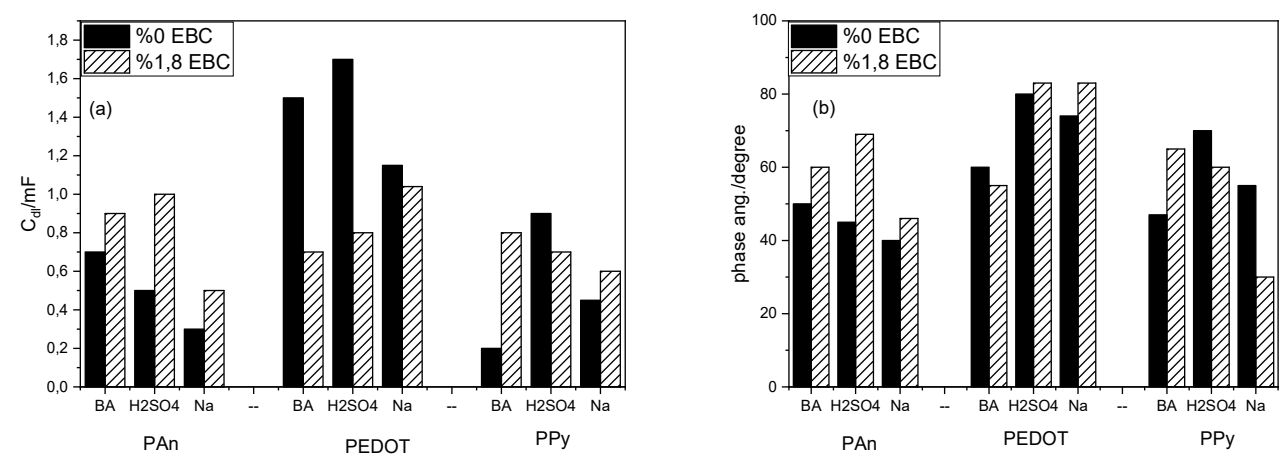

Figure 3. The Impedance graphs of CF coated with different conditions by CPE method. a) The $\mathrm{C}_{\mathrm{DL}}$ graph, b) The Phase Angle graph.

When it was looked at the Figure 3 it can be seen that $\mathrm{C}_{\mathrm{DL}}$ and Phase Angle were parallel together.

The experiments were carried out in cyclic voltammetry (CV) because of that to investigate the electrical and capacitive manner of CFs coated with different conducting polymer by controlled potential method. The applied conditions and used parameters of electrocoating were same the in CPE method, except for CF brush form. The single $\mathrm{CFs}$ were used for $\mathrm{CV}$ experiments. Read maximum current and the oxidation potential of each monomer (An, EDOT, Py) values were plotted in Figure 4 compared with $1.8 \%$ EBC.
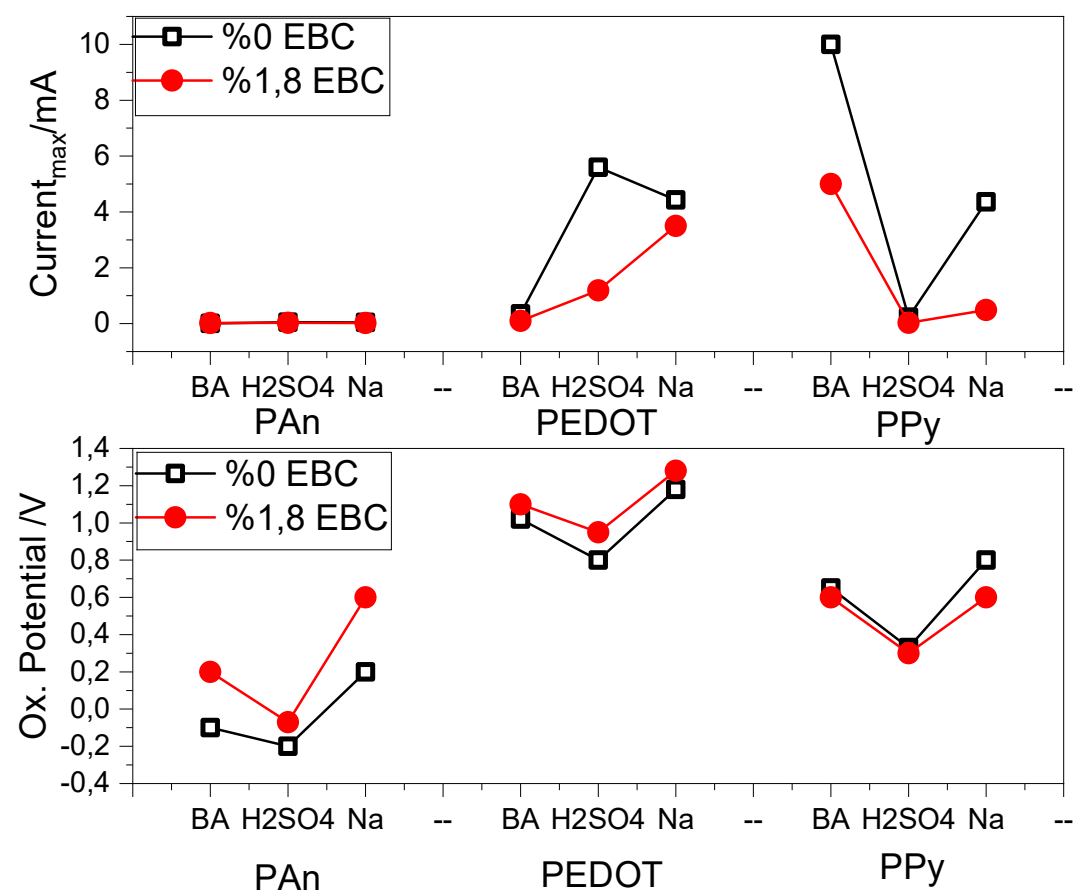

Figure 4. The comparison graphs of (a) The maximum current and (b) The oxidation potential belonging to PAn, PEDOT and PPy coatings obtained in different electrocoating conditions.

According to data, the oxidation was observed at lower potential in $\mathrm{H}_{2} \mathrm{SO}_{4}$ electrolyte solution for all monomers compared with other solutions. Beside this, in presence of EBC the potential was increased for PAn and PEDOT when it was decreased for Py. Imax values were changed for each polymer and conditions. Lowest value was read as $0.35^{*} 10^{-5} \mathrm{~A}$ for PEDOT in BA and $0.23 * 10^{-5} \mathrm{~A}$ for PPy in $\mathrm{H}_{2} \mathrm{SO}_{4}$. In presence of EBC the value was not changed importantly but, it was decreased for PEDOT and PPy and electrolytes. The biggest decreasing was $4.5^{*} 10^{-5} \mathrm{~A}$ in $\mathrm{H}_{2} \mathrm{SO}_{4}$ for PEDOT and $5 * 10^{-5} \mathrm{~A}$ in BA for PPy. 
The CFs coated with different electropolymerization conditions such as monomer, electrolyte, solvent and adding EBC by $\mathrm{CV}$ method were scanned in monomer free solution at different rates and at electrocoating potential range to investigate the capacitive and electrical properties of the CFs. Addition obtained this data supplied the information about if the electropolymerization mechanism was controlled by diffusion in absence/presence of EBC. In this section it was taken advantage of Randles-Sevcik equation.

In electrochemistry, this equation describes the effect of scan rate on the peak current of the oxidation and reduction $\left(\mathrm{I}_{\mathrm{p}}\right)$.

Or, if the solution is at $25^{\circ} \mathrm{C}$,

$$
I_{p}=0,4463 n F A C \sqrt{\left(\begin{array}{c}
n F v D \\
R T
\end{array}\right)}
$$

$$
I_{p}=2,65 * 10^{5} \mathrm{ACn}^{3 / 2}(\mathrm{Dv})^{1 / 2}
$$

In electrocoated process, the current passing through the electrode coated with conducting polymer is limited by the diffusion of species to the electrode surface from electrolyte solution medium. This diffusion flux is affected by the ingredients of electrolyte solution and the species at the electrode. As the plots of Ip vs. $\mathrm{v}^{1 / 2}$ was linear, it can say that the redox process was a chemically reversible process. So, obtained the oxidation $\left(\mathrm{I}_{\text {pox. }}\right)$ and reduction $\left(\mathrm{I}_{\mathrm{pred}}\right.$.) current peak values in different scan rates were illustrated for each monomer and electrolyte solution in Figure 5.

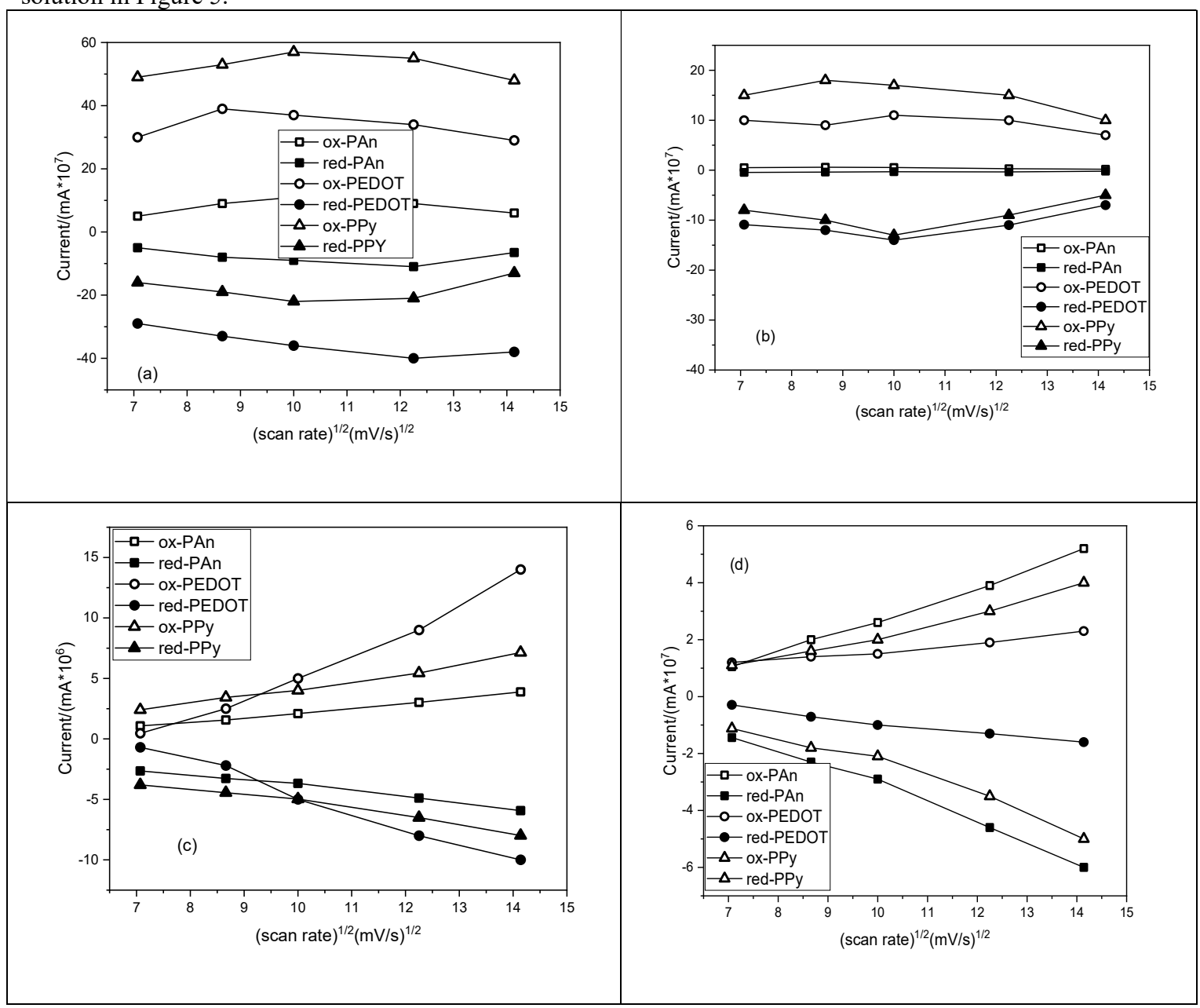



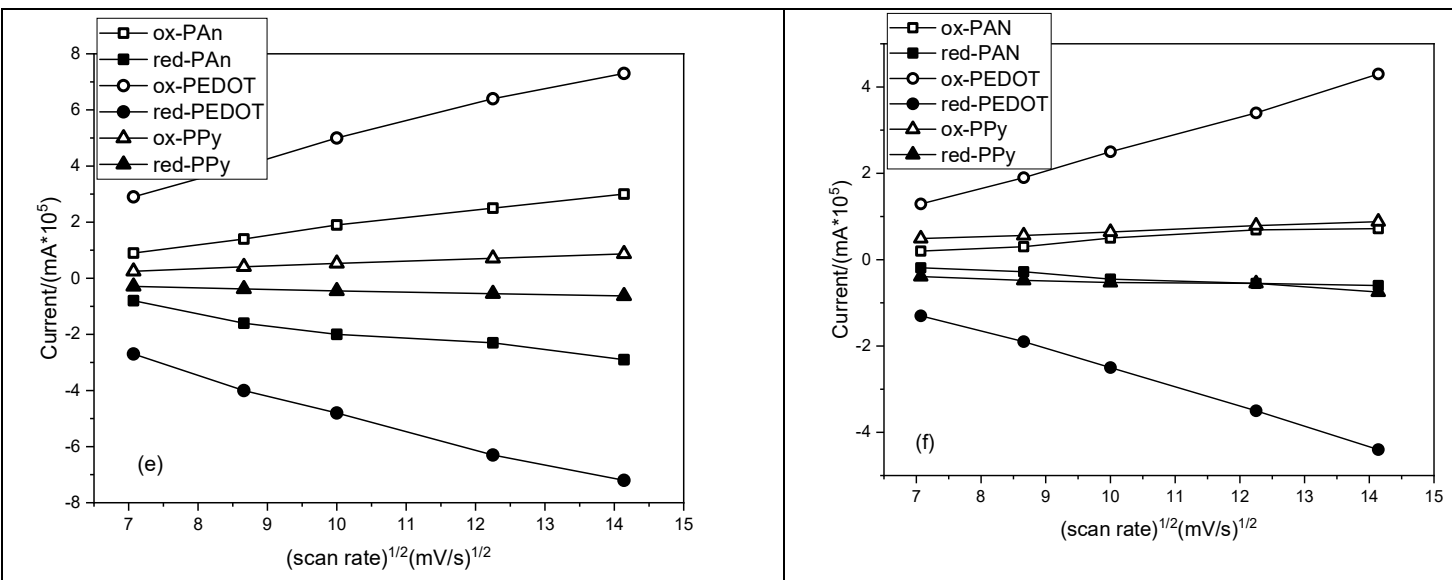

Figure 5. The graphs of the ox. and red. peak current vs. the square root of scan rate. a) $\mathrm{BA}-\mathrm{H}_{2} \mathrm{O}-0 \% \mathrm{EBC}$; b) BA- $\mathrm{H}_{2} \mathrm{O}-1.8 \%$ EBC; c) $\mathrm{H}_{2} \mathrm{SO}_{4}-\mathrm{H}_{2} \mathrm{O}-0 \% \mathrm{EBC}$; d) $\mathrm{H}_{2} \mathrm{SO}_{4}-\mathrm{H}_{2} \mathrm{O}-1.8 \%$ EBC; e) $\mathrm{NaClO}_{4}-\mathrm{ACN}-0 \%$ EBC; f) $\mathrm{NaClO}_{4}-\mathrm{ACN}-1.8 \%$ EBC.

According to Randles-Sevcik equation, obtained plots in $\mathrm{BA}-\mathrm{H}_{2} \mathrm{O}$ were not linear for all polymers (Figure 5a, c, e). In this case, it can be said that the redox process was not controlled by diffusion under this conditions. On the other hand, it was seen that all the redox processes carried out in $\mathrm{NaClO}_{4}-\mathrm{ACN}$ electrolyte solution were controlled by diffusion for each polymer coated CFs due to linear plot. In this conditions diffusion coefficient (D) was bigger than that of the Pan and PPy for PEDOT, because of high $\mathrm{I}_{\mathrm{p}}$ value.

To investigate whether the redox process was controlled by diffusion or not in presence of \% $1.8 \mathrm{EBC}$ in electrolyte solution, scanning at different rates were performed in the same conditions but adding \%1.8 EBC. Taken data were plotted in Figure 5b, d, e for BA- $\mathrm{H}_{2} \mathrm{O}, \mathrm{H}_{2} \mathrm{SO}_{4}-\mathrm{H}_{2} \mathrm{O}$ and $\mathrm{NaClO}_{4}-\mathrm{ACN}$, respectively.

In presence of $\mathrm{EBC}$ it could be say that redox process was controlled by diffusion in $\mathrm{BA}-\mathrm{H}_{2} \mathrm{O}$ for PAn in comparison with others. But $\mathrm{D}$ was low due to $\mathrm{I}_{\mathrm{p}}$ value. The process was proceeded by controlling with diffusion in $\mathrm{NaClO}_{4}$-ACN for PEDOT but not for Pan and PPy. This result was seen in previous study for PPy in same medium (Dolas et.al. 2016).

According to the determined results, it could be concluded that redox process mechanism was controlled or not by diffusion as depending on the used polymer and the species in electrolyte solution. This case might be attributed to the interaction of polymer and the species in electrolyte.

The $\mathrm{C}_{\mathrm{DL}}$ and phase degree of the CFs coated with PAn, PEDOT or PPy in the above mentioned electrolyte conditions were given in Figure 6. 

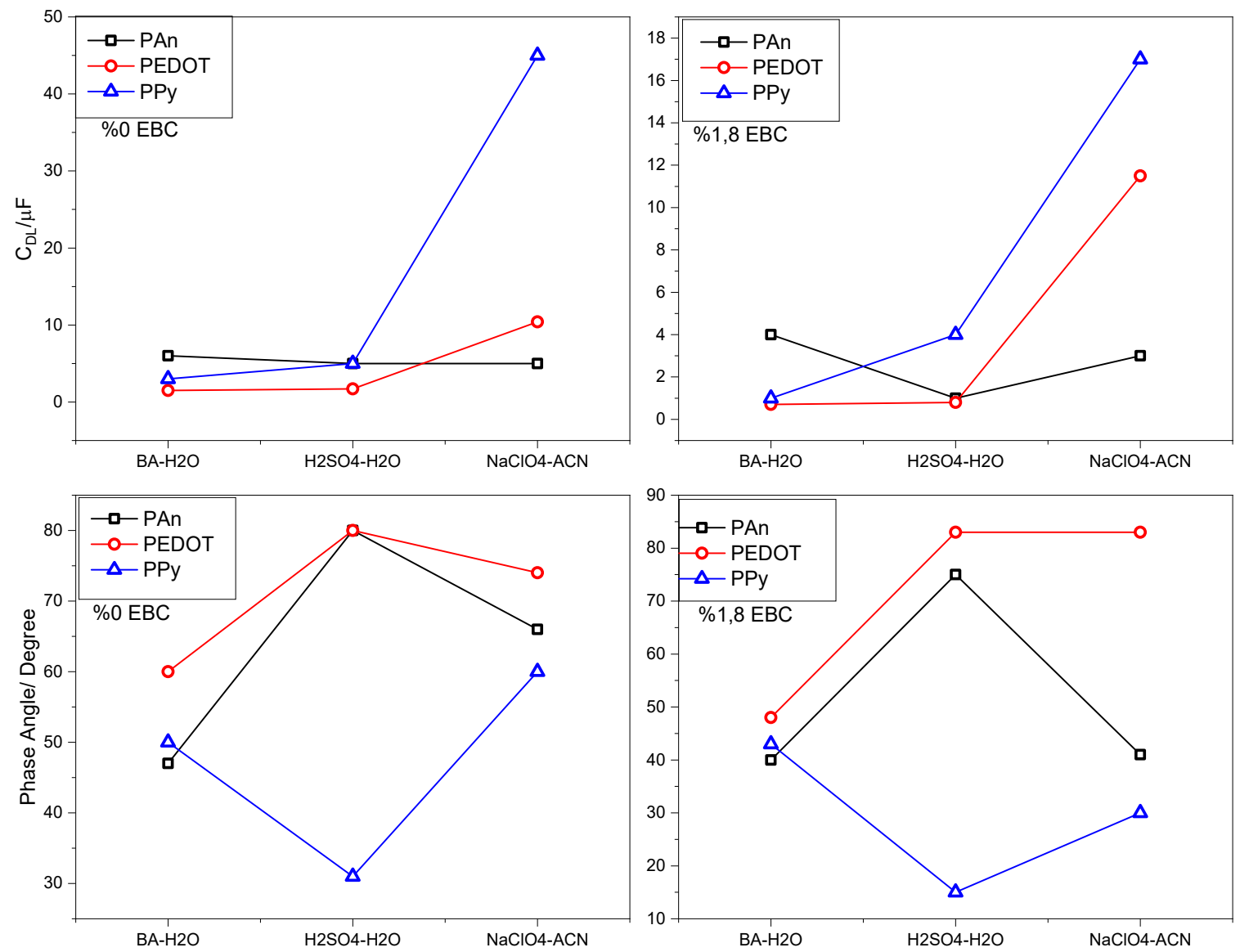

Figure 6. The Impedance graphs of $\mathrm{CF}$ coated with different conditions by $\mathrm{CV}$ method. a) The $\mathrm{C}_{\mathrm{DL}}$ graph, b) The Phase Angle graph.

The plots written $1.8 \% \mathrm{EBC}$ in the figure expressed the presence of $1.8 \% \mathrm{EBC}$ in electrolyte solution. When it was comparatively looked at the plots it was seen that the $\mathrm{C}_{\mathrm{DL}}$ value was decreased in every electrolyte solution for each one polymer in presence of $1.8 \% \mathrm{EBC}$ in electrolyte solution. So, this value was decreased to $4 \mu \mathrm{F}$ from $6 \mu \mathrm{F}$; to $0.7 \mu \mathrm{F}$ from $1.5 \mu \mathrm{F}$; to $1 \mu \mathrm{F}$ from $3 \mu \mathrm{F}$ in BA- $\mathrm{H}_{2} \mathrm{O}$ for Pan, PEDOT and PPy respectively. This decreasing trend was seen in the other conditions for the polymers. But, $\mathrm{C}_{\mathrm{DL}}$ was increased to $11.5 \mu \mathrm{F}$ from 10.4 $\mu \mathrm{F}$ in $\mathrm{NaClO}_{4}-\mathrm{ACN}$ for PEDOT. Phase angle was in the same trend. The feature was increased to $83^{\circ}$ from $74^{\circ}$ in $\mathrm{NaClO}_{4}-\mathrm{ACN}$ for PEDOT while it was decreased in all electrolyte solutions for Pan and PPy in presence of EBC.

The electropolymerization of conducting polymers were started by applied a potential at a certain of voltage. The electron motion was supplied due to the resonance structure of monomer ring. Thus, formed polymer chain was closed to electrode (here $\mathrm{CF}$ ) and $\mathrm{CF}$ was coated with conducting polymer. This formation was represented as the coating of CF with PEDOT in Figure 7. 

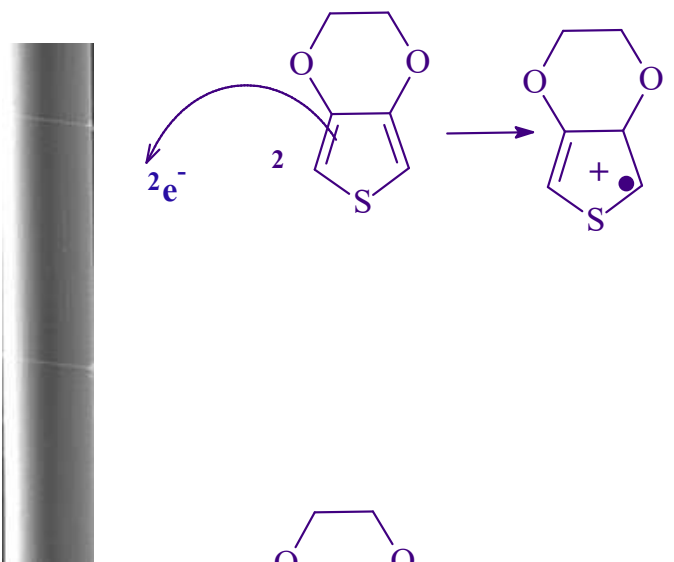<smiles>C[In]1C=C2OCCO[C@@H]2C=[SH]1</smiles><smiles>C1=C2OCCOC2[C@H]2SC=C3OCCO[C@H]3[C@@H]12</smiles><smiles>CI</smiles><smiles>c1sc(-c2scc3c2OCCO3)c2c1OCCO2</smiles><smiles>c1sc(-c2scc3c2OCCO3)c2c1OCCO2</smiles><smiles>C1COCCO1</smiles>

$\mathrm{e}^{-}$<smiles>CC1=C[SH]=C(c2scc3c2OCCO3)C1C</smiles><smiles>CCOc1c(-c2sc(-c3sc(-c4sc(CC)c5c4OCCO5)c4c3OCCO4)c3c2OCCO3)sc2c1OCCO2</smiles>

Figure 7. The presentation of the coating CF with PEDOT by CV method in electrolyte solution.

The motion of electron and monomer were affected by the structure and type of species in solution. So, the morphological differences were formed by this effects. For this reason, to show these differences, the SEM images of coated CFs were given in Figure 8. Figure $8 \mathrm{~b}$ and $8 \mathrm{~d}$ presented the SEM image of $5 \mathrm{mM}$ PEDOT and $5 \mathrm{mM}$ PPy coated $\mathrm{CF}$ in presence of $\mathrm{EBC}$ in $\mathrm{NaClO}_{4} / \mathrm{CAN}$, respectively. 

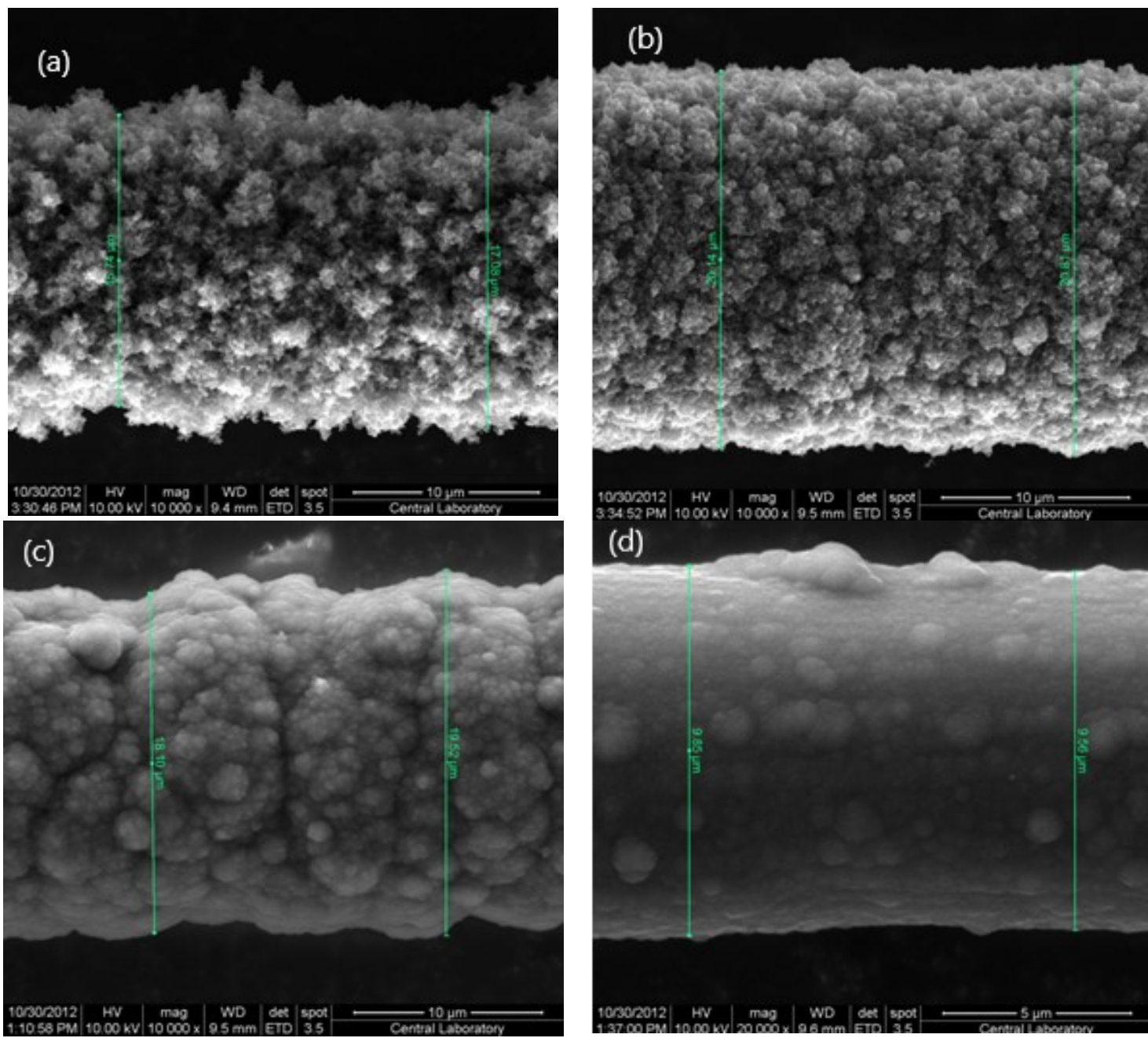

Figure 8. The SEM images the $\mathrm{CF}$ coated with a) PEDOT in $\mathrm{NaClO}_{4}-\mathrm{ACN}$, b) PEDOT in $\mathrm{NaClO}_{4}-\mathrm{ACN}-\% 1.8$ EBC, c) PPy in $\mathrm{NaClO}_{4}-\mathrm{ACN}$, b) PPy in $\mathrm{NaClO}_{4}-\mathrm{ACN}-\% 1.8$ EBC.

It can be seen that the texture coatings were more compact in the presence of EBC in electrolyte solution than that of the absence of EBC for PPy coated CF. The radius of PPy coated CF was measured as $9.85 \mu \mathrm{m}$ in $\% 1.8$ EBC (Figure 8d), while it was measured as 18.10 in \%0 EBC. On the contrary, according to taken SEM images the texture coating were more compact in the absence of $\mathrm{EBC}$ in electrolyte solution. The radius of PEDOT coated $\mathrm{CF}$ was measured as 17.05 for $\% 0 \mathrm{EBC}$, while it was measured as 20.14 for $\% 1.8 \mathrm{EBC}$. This manner can be attributed to the interaction and/or tendency in between the monomer and $\mathrm{EBC}$ due to their chemical structures.

Obtained $\mathrm{C}_{\mathrm{DL}}$ and radius data were compared to determine the relationship of between the radius of coating and the $\mathrm{C}_{\mathrm{DL}}$ of the coated CF. Thus, the data were given Table 1 .

Table 1: The relationship of between the radius of coating and the $\mathrm{C}_{\mathrm{DL}}$ of the coated $\mathrm{CF}$

\begin{tabular}{|l|l|l|l|l|}
\hline \multirow{2}{*}{ Conditions } & \multicolumn{2}{|l|}{ PEDOT } & PPy & Radius $/ \mu \mathrm{m}$ \\
\cline { 2 - 5 } & $\mathrm{C}_{\mathrm{DL}} / \mu \mathrm{F}$ & Radius $/ \mu \mathrm{m}$ & $\mathrm{C}_{\mathrm{DL}} / \mu \mathrm{F}$ & 18.10 \\
\hline $0 \% \mathrm{EBC}$ & 10.4 & 17.05 & 45 & 9.85 \\
\hline $1,8 \% \mathrm{EBC}$ & 11.5 & 20.14 & 17 & $\mathrm{C}$ \\
\hline
\end{tabular}

As according to the data in Table 1, it was seen that the relationship of between the radius of coating and the CDL of the coated CF was proportional. The relationship was proved that as radius was increased, capacitance value was increased as it was in PEDOT sample and as radius was decreased, capacitance value was decreased as it was in PPy sample. 


\section{Conclusion:}

In this study, it was investigated CFs were coated electrochemically with three different monomers (An, EDOT or Py) in different condition such as electrolyte $\left(\mathrm{BA}, \mathrm{H}_{2} \mathrm{SO}_{4}\right.$ or $\left.\mathrm{NaClO}_{4}\right)$, solvent $\left(\mathrm{H}_{2} \mathrm{O}\right.$ as inorganic medium or $\mathrm{ACN}$ as organic medium), in presence of foreign material (EBC) and coating method (constant potential and cyclic voltammetry as controlled potential). Obtained CFs coated with conducting polymer different conditions were compared with regard to electrical and capacitive and morphological features. These features were the current passed in the system, the weight of coating, $\mathrm{C}_{\mathrm{DL}}$, phase angle, ox. and red. Peak current, diffusion controlling, the radius of coating, the texture of coating.

It was determined that in $\mathrm{CPE}$, the current passed in the system was reached to about range of 6-7 A for PEDOT sample, 1-1.5A for Pan and 17-18 A for PPy. Thus the current was decreased in $\mathrm{BA}-\mathrm{H}_{2} \mathrm{O}$ and $\mathrm{H}_{2} \mathrm{SO}_{4}-\mathrm{H}_{2} \mathrm{O}$ medium due to the interaction of monomer and electrolyte. It was seen that the current flown in system was changed in certain values for each monomer by adding the EBC in electrolyte solution as \%1.8 (w/w). But this changing was more for Py than that for the other. When it was not remarkably for An and EDOT monomers, with compared to Py. This case was concluded that the case was based on the interaction of between monomer or electrolyte and EBC.

According to data, the oxidation was observed at lower potential in $\mathrm{H}_{2} \mathrm{SO}_{4}$ electrolyte solution for all monomers compared with other solutions. Beside this, in presence of EBC the potential was increased for PAn and PEDOT when it was decreased for Py. Imax values were changed for each polymer and conditions.

According to Randles-Sevcik equation, obtained plots in $\mathrm{BA}-\mathrm{H}_{2} \mathrm{O}$ were not linear for all polymers. In this case, it could be concluded that the redox process was not controlled by diffusion under this conditions. On the other hand, it was seen that all the redox processes carried out in $\mathrm{NaClO}_{4}-\mathrm{ACN}$ electrolyte solution were controlled by diffusion for each polymer coated CFs due to linear plot. In this conditions diffusion coefficient (D) was bigger than that of the Pan and PPy for PEDOT, because of high $I_{p}$ value.

In presence of EBC it could be concluded that redox process was controlled by diffusion in $\mathrm{BA}-\mathrm{H}_{2} \mathrm{O}$ for $\mathrm{PAn}$ in comparison with others. But $\mathrm{D}$ was low due to $\mathrm{I}_{\mathrm{p}}$ value. The process was proceeded by controlling with diffusion in $\mathrm{NaClO}_{4}-\mathrm{ACN}$ for PEDOT but not for Pan and PPy.

As seen that the related plots, the $\mathrm{C}_{\mathrm{DL}}$ value was decreased in every electrolyte solution for each one polymer in presence of $1,8 \% \mathrm{EBC}$ in electrolyte solution. So, this value was decreased to $4 \mu \mathrm{F}$ from $6 \mu \mathrm{F}$; to $0.7 \mu \mathrm{F}$ from $1.5 \mu \mathrm{F}$; to $1 \mu \mathrm{F}$ from $3 \mu \mathrm{F}$ in $\mathrm{BA}-\mathrm{H}_{2} \mathrm{O}$ for Pan, PEDOT and PPy respectively. This decreasing trend was seen in the other conditions for the polymers. But, $\mathrm{C}_{\mathrm{DL}}$ was increased to $11.5 \mu \mathrm{F}$ from $10.4 \mu \mathrm{F}$ in $\mathrm{NaClO}_{4}-\mathrm{ACN}$ for PEDOT. Phase angle was in the same trend. The feature was increased to $83^{\circ}$ from $74^{\circ}$ in $\mathrm{NaClO}_{4}-\mathrm{ACN}$ for PEDOT while it was decreased in all electrolyte solutions for Pan and PPy in presence of EBC.

The texture coatings were more compact in the presence of $\mathrm{EBC}$ in electrolyte solution than that of the absence of $\mathrm{EBC}$ for PPy coated $\mathrm{CF}$. When obtained $\mathrm{C}_{\mathrm{DL}}$ and radius values from different from conditions were compared it was seen that the relationship of between the radius of coating and the $\mathrm{C}_{\mathrm{DL}}$ of the coated $\mathrm{CF}$ was proportional. Thus, it may be concluded that the $\mathrm{C}_{\mathrm{DL}}$ and radius of coating were affected with the presence of different material/compound in electrolyte solution.

\section{References:}

Ahmed M. S., Jeong H., You J.-M. \& Jeon S., (2012). Synthesis and characterization of an electrochromic copolymer based on 2,2 $\square: 5 \square, 2 \square \square$-terthiophene and 3,4-ethylenedioxythiophene Physicochemical properties of electrochemically prepared polypyrrole perchlorate, Applied Nanoscience, vol. 2, no. 2, pp. 133-141

Ahonen H. J., Lukkari J., and Kankare J., (2000). n- and p-doped poly(3,4-ethylenedioxythiophene): two electronically conducting states of the polymer, Macromolecules. vol. 33, no. 18, pp. 6787-6793

Bhadra S., Khastgir D., Singha N. K., and Lee J. H., (2009). Progress in preparation, processing and applications of polyaniline, Progress in Polymer Science. vol. 34, no. 8, pp. 783-810

Bubert H., Ai X., Haiber S., Heintze M., Bruser V., Pasch E., Brandle W. \& Marginean G., (2002). Basic analytical investigation of plasma-chemically modified carbon fibers, Spectrochim. Acta B. 57, 1601-1610

Cysewska K., Karczewski J. \& Jasinski P., (2015). Influence of ' electropolymerization conditions on the morphological and electrical properties of PEDOT film, Electrochimica Acta, vol. 176, Article ID 25282, pp. $156-161$ 
Dhawan S. K., Kumar D., Ram M. K., Chandra S., and Trivedi D. C., (1997). Application of conducting polyaniline as sensor material for ammonia, Sensors and Actuators B: Chemical, vol. 40, no. 2-3, pp. 99-103

Dilsiz N., Erinc N.K., Bayramli E. \& Akovali G., (1995). Surface energy and mechanical properties of plasmamodified carbon fibers, Carbon. 33 853-858

Dolas H, Sarac AS. (2012). Electrosynthesis of Poly(3-dodecyl thiophene) in Acetonitrile with Boron Trifluoride Diethyl Etherate: The Effect of the Electrolyte on Electrochemical Impedance and Morphology, Journal of The Electrochemical Society. 159 (1) D1-D8

Dolas H., Giray D. and Sarac A.S., (2016). Effect of the Sizing Compound on the Electropolymerization of Pyrrole and the Impedance of Carbon Fiber Coated with Polypyrrol, Journal of Turkish Chemical Society-A JOTCSA. 3(3): 281-298, (2016)

Febo S., Leonardo F., Mario P. \& Luca P., (2002). Chemical modification of carbon fiber surfaces, Carbon. 40, $735-741$

Groenendaal L., Jonas F., Freitag D., Pielartzik H., and Reynolds J. R., (2000). Poly(3,4ethylenedioxythiophene) and its derivatives: past, present, and future, Advanced Materials, vol. 12, no. 7, pp. 481-494

Gulyas J., Foldes E., Lazar A. \& Pukanszky B., (2001). Electrochemical oxidation of carbon fibres: surface chemistry and adhesion, Compos. A. 32, 353-360

Jaymand M., (2013). Recent progress in chemical modification of polyaniline Dedicated to Professor Dr. Ali Akbar Entezami. Progress in Polymer Science, vol. 38, no. 9, pp. 1287-1306

Jeong R. A., Lee G. J., Kim H. S., Ahn K., Lee K., and Kim K. H., (1998). Physicochemical properties of electrochemically prepared polypyrrole perchlorate, Synthetic Metals, vol. 98, no. 1, pp. 9-15, (1998)

Kawashima H. and Goto H., (2011). Preparation and properties of polyaniline in the presence of trehalose, Soft Nanoscience Letters, vol. 1, no. 3, pp. 71-75

Kulandaivalu S., Zainal Z., and Sulaiman Y., (2015). A New Approach for Electrodeposition of poly (3, 4ethylenedioxythiophene)/ polyaniline (PEDOT/PANI)Copolymer, International Journal of Electrochemical Science, vol. 10, no. 11, pp. 8926-8940

Kumru ME, Springer J, Saraç AS, Bismarck A. (2001). Electrografting of thiophene, carbazole, pyrrole and their copolymers onto carbon fibers: electrokinetic measurements, surface composition and morphology. Synthetic Metals. 123(3):391-401

Li J., Huang Y., Xu Z. \& Wang Z., (2005). High-energy radiation technique treat on the surface of carbon fiber, Mater. Chem. Phys. 94, 315-321

Li N., Shan D., and Xue H., (2007). Electrochemical synthesis and characterization of poly(pyrrole-cotetrahydrofuran) conducting copolymer, European Polymer Journal, vol. 43, no. 6, pp. 2532-2539

Ma L., Su L., Zhang J., (2016). A controllable morphology GO/ PANI/metal hydroxide composite for supercapacitor, Journal of Electroanalytical Chemistry, vol. 777, pp. 75-84

Montes-Moran M.A., Gauthier W., Martinez-Alonso A. \& Tascon J.M.D., (2004). Mechanical properties of high-strength carbon fibers validation of an end-effect model for describing experimental data. Carbon. 42, $1275-1278$

Montes-Moran M.A., Martinez-Alonso A., Tascon J.M.D. \& Young (2001). Effects of plasma oxidation on the surface and interfacial properties of ultra-high modulus carbon fibres, Composites. 32, 361-371

Patil D. S., Pawar S. A., Hwang J., Kim J. H., Patil P. S., and Shin J. C., (2016). Silver incorporated PEDOT: PSS for enhanced electrochemical performance, Journal of Industrial and Engineering Chemistry, vol. 42, pp. $113-120$

Patil D. S., Pawar S. A., Kim J. H., Patil P. S., and Shin J. C., (2016). Facile preparation and enhanced capacitance of the Ag-PEDOT:PSS/ polyaniline nanofiber network for supercapacitors, Electrochimica Acta, vol. 213, pp. 680-690

Sarac AS, Sezgin S, Ates M, Turhan CM, Parlak EA, Irfanoglu B. (2008). Electrochemical impedance spectroscopy of poly(N-methyl pyrrole) on carbon fiber microelectrodes and morphology, Progress in Organic Coatings. 62(3):331-5

Shirakawa H., Louis E. J., MacDiarmid A. G., Chiang C. K. \& Heeger A. J., (1977). Synthesis of electrically conducting organic polymers: halogen derivatives of polyacetylene, $(\mathrm{CH}) x$, Journal of the Chemical Society, Chemical Communications, no. 16, pp. 578-580 
Saville P., (2005). Polypyrrole, Formation and Use, Defence Research and Development Atlantic Dartmouth, Dartmouth, Canada, (2005).

Wei Y., Tian J., and Yang D.,(1991). A new method for polymerization of pyrrole and derivatives, Makromolekulare Chemie, Rapid Communications, vol. 12, no. 11, pp. 617-623

Xu Z., Huang Y., Zhang C., Liu L., Zhang Y. \& Wang L., (2007). Effect of x-ray irradiation grafting on the carbon fibers and interfacial adhesion of epoxy composites, Compos. Sci. Technol. 67 3261-3270

Yue Z.R., Jiang W., Wang L., Gardner S.D. \& Pittman Jr. C.U.. (1999). Surface characterization of electrochemically oxidized carbon fibers. Carbon. 37 1785-1796 